Abstracta Iranicanica

Revue bibliographique pour le domaine irano-aryen

Volume 40-41 | 2019

Comptes rendus des publications de 2017-2018

\title{
Sergey Minov. « Date and Provenance of the Syriac Cave of Treasures: A Reappraisal »
}

\section{Christelle Jullien}

\section{(2) OpenEdition \\ 12 Journals}

\section{Édition électronique}

URL : http://journals.openedition.org/abstractairanica/50936

DOI : 10.4000/abstractairanica.50936

ISBN : 1961-960X

ISSN : 1961-960X

Éditeur :

CNRS (UMR 7528 Mondes iraniens et indiens), Éditions de l'IFRI

Référence électronique

Christelle Jullien, «Sergey Minov. « Date and Provenance of the Syriac Cave of Treasures: A

Reappraisal » », Abstracta Iranica [En ligne], Volume 40-41 | 2019, document 13, mis en ligne le 30 décembre 2019, consulté le 24 avril 2021. URL : http://journals.openedition.org/abstractairanica/ 50936 ; DOI : https://doi.org/10.4000/abstractairanica.50936

Ce document a été généré automatiquement le 24 avril 2021.

Tous droits réservés 


\title{
Sergey Minov. « Date and Provenance of the Syriac Cave of Treasures: A Reappraisal »
}

\author{
Christelle Jullien
}

\section{RÉFÉRENCE}

Sergey Minov. « Date and Provenance of the Syriac Cave of Treasures: A Reappraisal ", Hugoye: Journal of Syriac Studies 20/1, 2017, p. 129-229

1 La Caverne des trésors est une composition pseudépigraphique attribuée à Éphrem le Syrien qui présente une fresque de l'histoire sacrée chrétienne. L'A., spécialiste reconnu de ce texte, rappelle qu'en raison de sa nature idiosyncratique, il n'est pas aisée de situer cette œuvre dans le monde pluriformel du christianisme syriaque de l'époque tardo-antique. Cet article d'une centaine de pages effectue un réexamen de certaines hypothèses de recherche sur la date et le milieu de rédaction, et offre de nouveaux arguments convaincants pour une meilleure contextualisation. Le texte aurait très probablement été rédigé entre le milieu $\mathrm{du} \mathrm{VI}^{\mathrm{e}}$ et les premières décennies $\mathrm{du}$ VII ${ }^{e}$ siècle. La réflexion sur la question de la provenance de l'œuvre est solidement engagée : selon l'A., la Caverne aurait été écrite par un chrétien syro-occidental qui vivait dans nord de la Mésopotamie sous contrôle sassanide. 


\section{AUTEURS}

\section{CHRISTELLE JULLIEN}

CNRS, Mondes iranien et indien, Paris 